CITATION: Sahin, O., Bertone, E., Baker, M., 2015. Evaluating design alternatives of constructed storm-water treatment wetlands, 2015 IEEE International Conference on Industrial Engineering and Engineering Management (IEEM), pp. 1452-1456.

\title{
Evaluating Design Alternatives of Constructed Storm-water Treatment Wetlands
}

\author{
O. Sahin ${ }^{1}$, E. Bertone ${ }^{1}$ and M. Baker ${ }^{1}$ \\ ${ }^{1}$ Griffith School of Engineering, Griffith University, Australia \\ o.sahin@griffith.edu.au
}

\begin{abstract}
In recent years, there has been a substantial increase in public awareness in regard to the issues related to climate change. This increase in awareness has led to the formation of the South East Queensland Climate Adaptation Research Initiative, with the primary objective to adapt the region for the impacts of climate change. As part of this initiative, this paper aims to select the best design alternatives for constructed wetland design for treatment of storm-water runoff in order to effectively treat storm-water runoff and subsequently to prepare the South East Queensland, Australia for the expected impacts of climate change. In this context, to identify and evaluate preferred adaptation alternatives, the authors have undertaken a multi-criteria analysis by using the AHP technique. The combined results of this exploratory study, display that across the three stakeholder groups; Public Health and Safety, Flooding and Drainage Control of highest priority respectively.
\end{abstract}

Keywords - Storm-water, Climate adaptation, Multicriteria analysis, AHP

\section{INTRODUCTION}

In Australia, the rainfall patterns are highly variable. In recent years, a trend towards increased extreme precipitation events has been observed across Australia. In 2010 and 2011 a very strong la-niña event caused the highest two year Australian average rainfall pattern on record [1-3].

The average temperature recorded in Australia is projected to rise, which is in stark comparison to recent temperature recordings. The frequency of drought will increase in parts of Australia, in comparison other areas will experience and increase in peak rainfall events[4].

Though, it is also likely that there will be more peak rainfall events in many areas. With this increase in severe climate events, it's fundamentally important that localised infrastructure be sufficiently prepared and of an adequate nature, to ensure a catastrophe does not occur. Infrastructure investment is costly and involves numerous stakeholders and many facets of decision making. In Australia, $64 \%$ of the population reside in capital cities located along the coastline and sensitive to extreme events. Therefore, it is extremely important that stormwater infrastructure should be prepared for the impacts of climate change and variability.

Storm-water management facilities are important elements of civil infrastructure and sensitive to extreme weather events, which generate peak runoff flows. Urban storm-water contains a range of pollutants and nutrients associated with fine sediments, these pollutants are filtered by natural wetland systems as storm-water flows through on its way to receiving lakes, waterways and oceans.

Constructed wetlands are man-made copies of these natural wetland systems, which utilise the same treatment mechanisms that exist in natural wetlands. As part of an urban landscape, constructed wetlands are expected to satisfy urban design objectives, such as flow control and flood protection, improving water quality and quantity and ecosystem health. Thus, an analysis of constructed storm-water treatment wetlands and practical implantation methods is an important issue in order to develop cost effective strategies to adapt the regions to the effects of changing climate and related extreme events.

As part of South East Queensland Climate Adaptation Research Initiative (SEQCARI) [5], this project aims to develop a decision making framework to select the best design alternatives for constructed wetland design for treatment of storm-water runoff within the Gold Coast region in SEQ, Australia, and then provide recommendations based upon these results to build a decision making framework.

\section{METHODOLOGY}

There exist a number of different types of constructed wetland design options. Noticeably, planning, design and constructing constructed storm-water wetlands are a big challenge in regards to decision making. The process is always complex and usually involves multiple stakeholders with different goals, numerous alternatives and conflicting multiple objectives. It must be noted that preferred adaptation design alternatives vary across Australia. For this project, Carrara situated in the Gold Coast Region was selected as a case study area.

As decision making is a process of selecting from among several alternatives based on various criteria, the decision based on a single criterion would be oversimplification of the characteristics of the problem under consideration, and therefore may lead to inappropriate decisions. In MCDA fields, a problem can be considered as a decision problem if there are at least two criteria (in some cases conflicting) to deal with, otherwise it would be a problem of getting the right information, not a decision problem [6, 7].

Several multi-criteria decision aid techniques are suitable for comparing multiple criteria, simultaneously, 
and for providing a solution to a given problem. While there are no better or worse techniques, some techniques are better suited to a particular decision problem [8].

The analytical hierarchy process (AHP) technique, despite some criticisms, has been selected for the current study. Criticisms of the AHP include; the difficulty of conversion from verbal to numeric scale; inconsistencies imposed by the 1 to 9 scale; a number of comparisons required may be large [9, 10]. However, AHP, owing to its flexibility to be integrated with different techniques, enables the user to extract benefits from all the combined methods and, hence, achieve the desired goal in an improved manner [11]. In addition, the AHP is set apart from other MCDA techniques because of the unique utilisation of a hierarchy structure to represent a problem in the form of a goal, criteria and alternatives [12]. This allows for a breakdown of the problem into various parts for pair wise comparisons, which uses a single judgement scale. Thus, the AHP has been widely used to solve various decision problems [13-20]. The underlying concept of the AHP technique is to convert subjective assessments of relative importance to a set of overall scores or weights [21]. The AHP, based on three principles as defined by Saaty, is an Eigen value approach to the pair-wise comparison [22].

Applying AHP to a given problem involves the implementation of three principles: decomposition, evaluation and synthesis. The basic process for the AHP technique is to construct a hierarchy with a number of levels depending on the problem. For a three level hierarchy structure, the levels may consist of a goal, objective for that particular goal and finally the alternatives considered. Once the hierarchy is constructed participants are required to make pairwise comparisons prioritising the objectives in regards to the goal and the priority of the alternatives in regards to the objectives.

Working down the AHP hierarchy; the first level consists of the goal, the second level is the stakeholders, the third level is the objectives and finally the fourth level is the alternatives. The goal for this project is selecting best design alternatives for constructed wetland design for the treatment of storm-water runoff. The stakeholders for this project consisted of people from the government sector, private sector and academic institution. The design alternatives and objectives for this project were identified through literature review and consultations with the expert stakeholders. A survey questionnaire was used to collect data from stakeholders.

\section{A. Constructing the AHP Hierarchy Structure}

In Fig.1, the hierarchy structure represents the goal, stakeholders, objectives and design alternatives for use with the AHP.

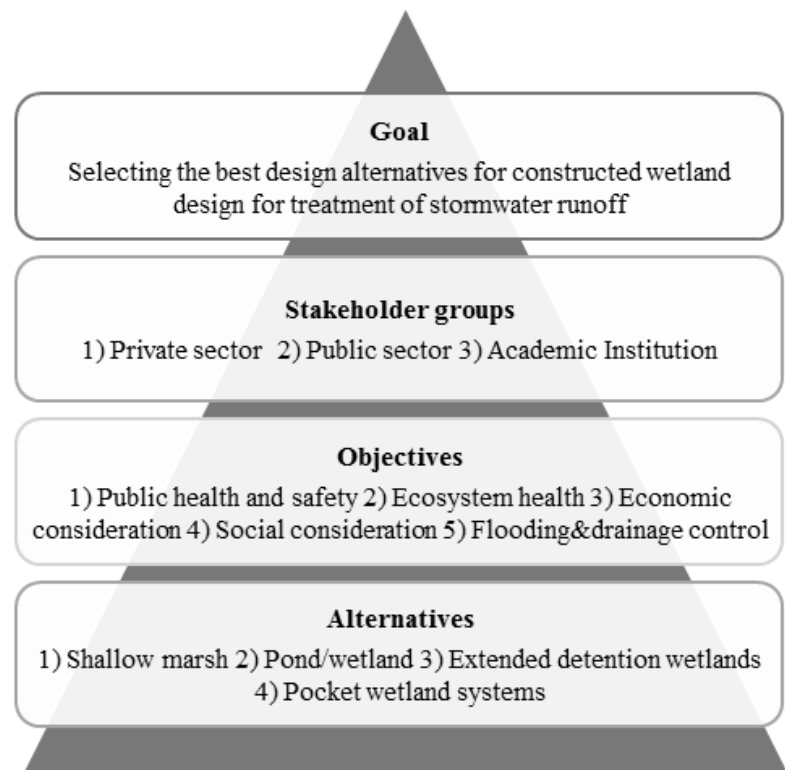

Fig. 1. AHP hierarchy structure

The most effective and efficient solutions to climate risk can be designed when academics, governments, business (private) stakeholders, and the public collaborate on potential solutions. Therefore, the experts from the public sector, private sector and academic institution within the Gold Coast region were consulted. The stakeholder groups were weighted within the hierarchy structure. This allows the goal to be influenced by the priority given to each stakeholder groups in that level. A number of case studies regarding resource management involving multiple stakeholders are listed by Harrison and Qureshi [23]. They observe, aside from a few exceptions, that weights were not strategically assigned to stakeholder groups or that no weights were assigned. In regards to the application of AHP for this project, it is evident that clear identification of stakeholder groups combined with assigning weights to stakeholder is deemed necessary to obtain a successful result.

The same hierarchy structure as shown in Fig. 1 was utilised for all participating stakeholders as this allowed them to answer a uniform set of questions. Therefore three different sets (of the same data) were obtained (one for each stakeholder group) which allowed for the comparison and identification of the differences between the stakeholder groups. The use of AHP in this manner allows for flexibility when combing participants' responses.

Based on multiple objectives outlined in the Australian guidelines for urban storm-water management [24], for this study, the following five objectives (criteria) are selected for MCDA analysis, after stakeholder consultation:

1) Public Health and Safety: To minimise the risk to public health from mosquitoes, the community/properties from flooding, and of injury or loss of life.

2) Ecosystem Health: To retain natural drainage systems, and protect ecosystem health and protect existing 
values of waterways, wetlands, estuaries, marine and associated vegetation from development impacts

3) Economic Considerations: To implement stormwater management systems which are economically viable in the long-term.

4) Social Considerations: To ensure that communities' social, aesthetic and cultural values are recognised and maintained when managing storm-water.

5) Flooding and Drainage Control: To protect the built environment from flooding and waterlogging.

And finally, four design alternatives based on existing literature and the consultations with expert stakeholders were identified as: 1) Shallow Marsh, 2) Pond/Wetland; 3) Extended Detention Wetlands; and 4) Pocket Wetlands Systems.

\section{RESULTS}

In regards to the validity of the results firstly, a consistency check was utilised. The AHP technique provides feedback in regard to the consistency of the judgements made by the participants, through a Consistency Ratio (CR). In regards to this project, the judgements made by each participant with respect to each objective with respect to the goal of selecting best design alternatives of constructed storm-water wetlands is expected to be consistent. A low CR means that the consistency of the participant's judgements is at a high level. A high $\mathrm{CR}$ indicates that the consistency of the participant's judgements is at a low level. The consistency of each participant results collected from the survey is shown in Table 1 below. For an environmental and engineering problem of this sought it is expected that the consistency ratio should be not greater than 0.2 [12]. This Implies a maximum of $20 \%$ inconsistency is tolerated for the problem. As seen in Table 1, there is an overall low level of the inconsistency of the participant's judgements. This can infer that the data collected is suitable for making recommendations for use in the Gold Coast region.

TABLE I

CONSISTENCY RATIOS OF PARTICIPANTS JUDGMENTS

\begin{tabular}{lc}
\hline \multicolumn{1}{c}{ Stakeholder groups } & Consistency ratio \\
\hline Public sector & 0.948 \\
Private sector & 0.175 \\
Academic institution & 0.166 \\
\hline
\end{tabular}

The data analysis consists of looking at the weights allocated to each stakeholder group as the weighting assigned to each stake holder group affects the results of priorities of the objectives and the alternatives when computed. Using a questionnaire survey, participants were asked which stakeholder group had a greater role on developing and implementing the design alternatives for the constructed storm-water wetlands. Based on the participants' responses, 43 percent, 39 percent, and 18 percent weights were assigned to Private Sector, Public Sector, and Academic Institution respectively.
A. The Priorities of the Objectives with Respect to Each Stakeholder Group

The combined data collected across the three stakeholder groups indicates that the most important objectives to consider when adapting constructed stormwater treatment wetlands to climate change, are Public Health and Safety along with Flooding and Drainage Control (Fig. 2). Considering the responses from the three stakeholder groups it indicates that there is a consistency pattern shown across the different objectives. The results show the next highest ranked objectives are Ecosystem Health and Economic considerations, with Social consideration of lowest priority. Economic and social considerations may be prioritized in this manner as with the recent flooding events around the region, these experts opinions at this point in time may be only considering the recent issues.

The objective with the highest percentage difference across the stakeholders is Flooding and Drainage Control, with a percentage difference of $8.0 \%$. This suggests that stakeholders have the most disagreement with this particular objective. The objective that has the lowest percentage difference is the Social Considerations objective, with a percentage difference of $2.5 \%$. This objective is also the least prioritised objective to consider within the region also. It should be noted, of the fact that across all of the objectives that the percentage difference is $8.0 \%$ or lower; which is lower than the design alternatives percentage difference. This again implies a relatively high level of agreement across the stakeholders, due to the fact the percentage differences are quite low.

The priorities of the objectives with respect to each stakeholder group were calculated. The private sector participants ranked Public Health \& Safety of a 0.339 priority, which was the highest priority. The objective Flooding and Drainage Control followed by Economic Considerations with a priority of 0.278 and 0.132 respectively. The private sector assigned Ecosystem Health and Social Considerations of least priority, 0.131 and 0.082 , respectively.

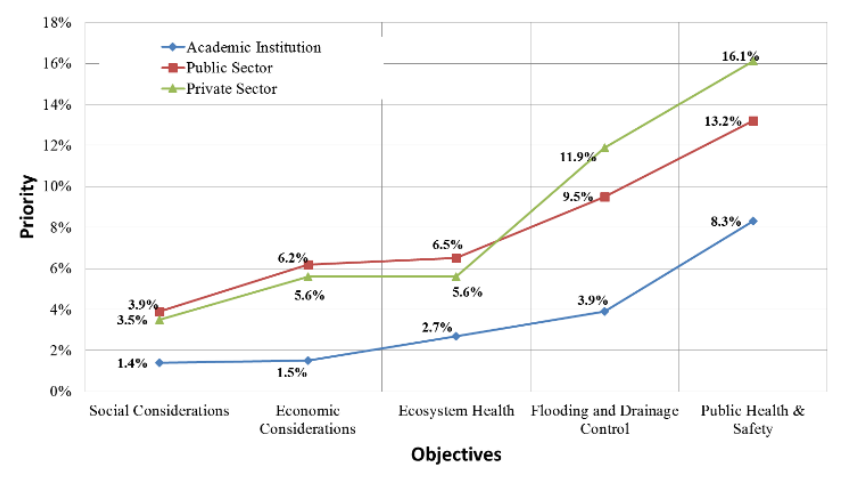

Fig. 2. Global objective priorities for stakeholders

The objective with the highest priority for the public sector participants was Public Health \& Safety with a priority of 0.335 , followed by Flooding and Drainage 
Control and Ecosystem Health with a priority of 0.242 and 0.165. The government sector found that the Economic Considerations and Social Considerations objectives were of least importance with a priority of 0.159 and 0.098 respectively. It is apparent that the government sector is considering climate change as a major factor when it comes to infrastructure; therefore putting forward objectives that are best suited to the impacts of severe weather events is most desirable. Finally, the participants from academic institution ranked Public Health \& Safety with the highest priority of 0.462 , followed by Flooding and Drainage Control and Ecosystem Health with a priority of 0.224 and 0.147 . The Economic Considerations and Social Considerations objectives were of least importance with a priority of 0.89 and 0.077 respectively.

B. The Priorities of the Design Alternatives with Respect to Objectives for Each Stakeholder Group

As a final step, the priorities of the design alternatives with respect to the objectives for each stakeholder group were calculated and a numerical value to define its priority each alternative were assigned The higher the numerical value the higher the priority, this defines each priority so that multiple alternatives can be compared.

The participants from the private sector ranked the Extended Detention Wetland system of a 0.339 priority, which was the highest priority, followed by the Pond/Wetland system with a priority of 0.328 . These two systems out of the four alternatives offer the maximum amount of flooding protection, which is an important issue to consider when adapting to climate change. The negatives to these two systems, however, are the cost to maintain especially the Pond/Wetland system and the low rates of pollutant breakdown for the Extended Detention Wetland system under extreme flows. The private sector assigned the Pocket Wetland and Shallow marsh system of least priority with a value of 0.227 and 0.106 respectively.

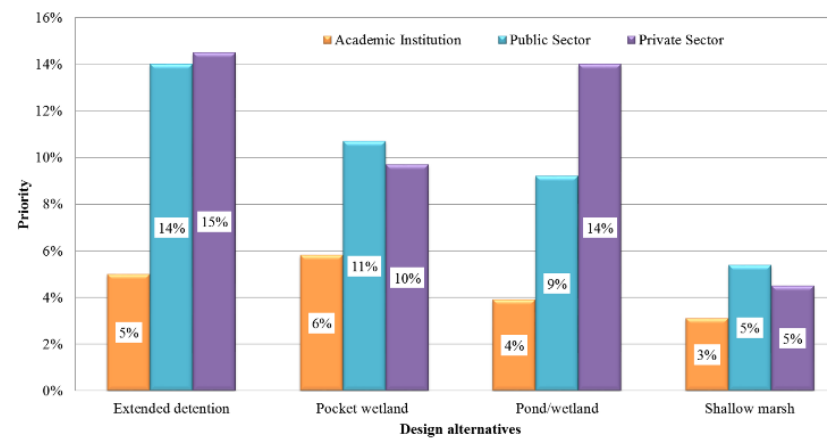

Fig. 3. Global alternative priorities for stakeholders

The participants from the public sector assigned the highest priorities to the Extended Detention Wetland System (0.452 priority) and the Pocket Wetland System (0.273 priority), and lowest priorities the Pond/Wetland (0.182) and Shallow Marsh (0.92) respectively.
The expert participants from the public and private sectors recognise that the need to adapt these wetlands to best suit the impacts of climate change is of a high priority indicating that the data collected is relatively consistent. The only inconsistency between these two stakeholder groups was the Pond/Wetland and Pocket Wetland alternative. The Private Sector prioritised the Pond/Wetland alternative just behind the Extended Detention Wetland system. The reason for this, might be the private sector usually has more to do with the construction and maintenance of these wetlands and knowing this they may understand that the Pond/Wetland alternative is more easily constructed and maintained compared to the Pocket Wetland System. According to the participants from the academic institution, the alternative of highest priority was Pocket Wetland System (0.327), followed by Extended Detention Wetland System (0.278). The academic institution found that the Pond/Wetland and Shallow Marsh alternative was of least importance with a priority of 0.172 and 0.101 respectively.

The results obtained from the academic institution rank the Pocket Wetland system as being the most appropriate alternative. This contradicts the two other stakeholder groups for the most preferred alternative. The academics view on this may be from an ecosystem health perspective. As the Pocket Wetland system when compared to the Extended Detention Wetland and Pond/Wetland system promotes greater ecosystem health. This is due to the fact that Pond/Wetland systems can create mosquito problems which can have alarming effects on resident's health. The drawback on the Extended Detention Wetland system is the low rate of pollutant breakdown under extreme flows.

Fig. 3 shows the global alternative priorities for each stakeholder groups. The design alternative with the highest percentage difference across the stakeholders is the Pond/Wetland system, with a percentage difference of $10.1 \%$. This suggests that this design alternative is the alternative that the stakeholders have the most disagreement with. The shallow marsh alternative has the lowest percentage difference of $2.3 \%$, this shows that across the stakeholders that this alternative is the least desirable to be implemented within the region. Must be noted that across all of the design alternatives that the percentage difference is approximately $10 \%$ or lower. This implies agreement across the stakeholders, which reinforces the fact that the stakeholders participating have expert knowledge regarding this topic.

\section{DISCUSSION AND CONCLUSION}

It is evident across three stakeholder groups that design alternatives should consider the following objectives respectively Public Health and Safety and Flooding and Drainage Control. The three stakeholders also concur when considering the impacts that climate change on constructed storm-water wetlands. That economic and social consideration should have a low importance when considering the design alternatives. 
It is obvious, that there are some differences across the three stakeholder groups when considering which design alternative should be implemented. Though with the highest weight assigned to the Private and Public Sectors respectively. This could infer that the academic institutions selection of the Pocket Wetland system could be disregarded. Which would indicate the Extended Detention Wetland system made by both the Private and Public Sectors would be implemented.

The differences and similarities between the stakeholder groups' priorities can lead to a number of important conclusions. The Private Sector and Public Sector groups were assigned with the highest weighting in regards to the project. This indicates that out of the other stakeholder groups that the participants believe that the Private Sector and Public Sector play the most important role when it comes to the decision making process on constructed storm-water treatment wetlands. This could be due to the fact that these sectors have a greater responsibility of designing and constructing these stormwater wetlands.

\section{REFERENCES}

[1] Sahin, O., R.S. Siems, R.A. Stewart, and M.G. Porter, Paradigm shift to enhanced water supply planning through augmented grids, scarcity pricing and adaptive factory water: A system dynamics approach. Environmental Modelling \& Software, 2014(0).

[2] Sahin, O., R.A. Stewart, and M.G. Porter, Water security through scarcity pricing and reverse osmosis: a system dynamics approach. Journal of Cleaner Production, 2015. 88(0): p. 160-171.

[3] Serrao-Neumann, S., et al., Improving cross-sectoral climate change adaptation for coastal settlements: insights from South East Queensland, Australia. Regional Environmental Change, 2013. 14(2): p. 489-500.

[4] CSIRO, Climate and water availability in south-eastern Australia a synthesis of findings from Phase 2 of the South Eastern Australian Climate Initiative (SEACI), in CSIRO Land and Water science report 1834-6618, D.A. Post, B. Timbal, and N.J. Potter, Editors. 2012, CSIRO: [Canberra, A.C.T. Australia]. p. 1 PDF (41 p.).

[5] Choy, D., et al., Adaptation Options for Human Settlements in South East Queensland - Main Report for the South East Queensland Climate Adaptation Research Initiative. 2012, Griffith University: Brisbane, Australia.

[6] Roy, B., Ranking and Choice in Pace of Multiple Points of View (Electre Method). Revue Francaise D Informatique De Recherche Operationnelle, 1968. 2(8): p. 57- 75.

[7] Keeney, R.L. and H. Raiffa, Decisions with multiple objectives : preferences and value tradeoffs. Wiley series in probability and mathematical statistics. 1976, New York: Wiley. xxviii, 569 p.

[8] Haralambopoulos, D.A. and H. Polatidis, Renewable energy projects: structuring a multi-criteria group decisionmaking framework. Renewable Energy, 2003. 28(6): p. 961-973.

[9] Ramanathan, R. and L.S. Ganesh, Energy resource allocation incorporating qualitative and quantitative criteria: An integrated model using goal programming and AHP. Socio-Economic Planning Sciences, 1995. 29(3): p. 197-218.
[10] Macharis, C., J. Springael, K. De Brucker, and A. Verbeke, PROMETHEE and AHP: The design of operational synergies in multicriteria analysis. Strengthening PROMETHEE with ideas of AHP. European Journal of Operational Research, 2004. 153(2): p. 307-317.

[11] Vaidya, O.S. and S. Kumar, Analytic hierarchy process: An overview of applications. European Journal of Operational Research, 2006. 169 p. 1-29.

[12] Saaty, T.L. and K.P. Kearns, Analytical Planning : The Organization of Systems International Series in Modern Applied Mathematics and Computer Science. Vol. 7. 1985, Oxford, New york: Pergamon Press.

[13] Awasthi, A. and S.S. Chauhan, Using AHP and DempsterShafer theory for evaluating sustainable transport solutions. Environmental Modelling \& Software, 2011. 26(6): p. 787-796.

[14] Bottero, M., E. Comino, and V. Riggio, Application of the Analytic Hierarchy Process and the Analytic Network Process for the assessment of different wastewater treatment systems. Environmental Modelling \&amp; Software, 2011. 26(10): p. 1211-1224.

[15] Crossman, N.D., B.A. Bryan, and D. King, Contribution of site assessment toward prioritising investment in natural capital. Environmental Modelling \& Software, 2011. 26(1): p. 30-37.

[16] Chen, Y. and Z. Paydar, Evaluation of potential irrigation expansion using a spatial fuzzy multi-criteria decision framework. Environmental Modelling \& Software, 2012. 38(0): p. 147-157.

[17] Gao, L. and A. Hailu, Ranking management strategies with complex outcomes: An AHP-fuzzy evaluation of recreational fishing using an integrated agent-based model of a coral reef ecosystem. Environmental Modelling \& Software, 2012. 31(0): p. 3-18.

[18] Sahin, O. and S. Mohamed, A spatial temporal decision framework for adaptation to sea level rise. Environmental Modelling \& Software, 2013(0).

[19] Sahin, O. and S. Mohamed, Coastal vulnerability to sealevel rise: a spatial-temporal assessment framework. Natural Hazards, 2013: p. 1-20.

[20] Sahin, O., van Staden, R.C., Chai, G., Guan, H. and Stewart, R. , Adapting Physical Infrastructure in South East Queensland and Impacts of Climate Change, in Responding to Climate Change Lessons from an Australian Hotspot, P. Burton, Editor. 2014, CSIRO Publishing: Brisbane, Qld, Australia. p. 216.

[21] Saaty, T.L., The Analytic Hierarchy Process. 1980, New York, NY: McGraw-Hill.

[22] Schmoldt, D.L., The analytic hierarchy process in natural resource and environmental decision making. Managing forest ecosystems. 2001, Dordrecht ; Boston: Kluwer Academic Publishers. xviii, $305 \mathrm{p}$.

[23] Harrison, S.R. and M.E. Qureshi, Choice of stakeholder groups and members in multicriteria decision models. Natural Resources Forum, 2000. 24(1): p. 11-19.

[24] ARMCANZ and ANZECC, Australian guidelines for urban stormwater management, 2000. National water quality management strategy. 2000, Canberra, A.C.T.: Agriculture and Resource Management Council of Australia and New Zealand and Australian and New Zealand Environment and Conservation Council. ii, 72 p. 